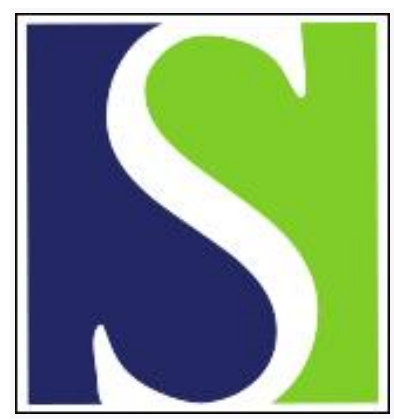

Scand J Work Environ Health 2004;30(2):129-138

https://doi.org/10.5271/sjweh.770

Issue date: Apr 2004

Urinary catecholamines and salivary cortisol on workdays and days off in relation to job strain among female health care providers

by Fujiwara K, Tsukishima E, Kasai S, Masuchi A, Tsutsumi A, Kawakami N, Miyake H, Kishi R

Affiliation: c/o Department of Hygiene and Preventive Medicine, Okayama University Graduate School of Medicine and Dentistry, 2-5-1 Shikata-cho, Okayama 700-8558, Japan. kkondo@med.hokudai.ac.jp

Refers to the following text of the Journal: 2000;26(4):306-316

The following article refers to this text: 2009;35(3):188-192

Key terms: adrenaline; day off; female; health care provider; job strain; noradrenaline; saliva; salivary cortisol; shift worker; urinary catecholamine; urine; woman; workday

This article in PubMed: www.ncbi.nlm.nih.gov/pubmed/15127783 


\title{
Urinary catecholamines and salivary cortisol on workdays and days off in relation to job strain among female health care providers
}

\author{
by Kyoko Fujiwara, MD, ${ }^{1}$ Eri Tsukishima, MD, ${ }^{1}$ Setsuko Kasai, MD, ${ }^{1}$ Ayumi Masuchi, PhD, ${ }^{2}$ Akizumi \\ Tsutsumi, MD, ${ }^{3}$ Norito Kawakami, MD, ${ }^{3}$ Hirotsugu Miyake, MD, ${ }^{4}$ Reiko Kishi, MD ${ }^{1}$
}

\begin{abstract}
Fujiwara K, Tsukishima E, Kasai S, Masuchi A, Tsutsumi A, Kawakami N, Miyake H, Kishi R. Urinary catecholamines and salivary cortisol on workdays and days off in relation to job strain among female health care providers. Scand J Work Environ Health 2004;30(2):129-138.
\end{abstract}

\begin{abstract}
Objectives This study examined the effects of psychosocial job strain on the excretion of neuroendocrine stress hormones (adrenaline, noradrenaline, and cortisol) on workdays and days off.

Methods Japanese female health care providers $(\mathrm{N}=16)$ filled out Karasek's job content questionnaire and had their neuroendocrine excretions (ie, urinary catecholamines and salivary cortisol) measured on a day off and on two workdays (one day shift and one night shift). After control for age and job experience as covariates, a repeated-measures analysis of variance was carried out.

Results Noradrenaline excretion was significantly greater over time in the high-strain group than in the lowstrain group, and that of the high-demand group was significantly greater over time than that of the low-demand group. Adrenaline excretion did not significantly differ between the groups. The group with high supervisory support had significantly higher adrenaline excretion than the group with low supervisory support. The concentration of salivary cortisol on a dayshift was significantly lower, but marginally, in the high-strain group than in the low-strain group.

Conclusions Psychosocial job strain is associated with greater noradrenaline excretion over time. This finding suggests unwinding sympathetic nervous activity. The low cortisol levels of the high-strain group may indicate circadian rhythm disturbance induced by job strain. Supervisory relationships may have a particular influence for the studied occupation because the participants had more administrative contact with supervisors than support at the worksite; therefore, supervisory support may increase adrenaline excretion.
\end{abstract}

Key terms adrenaline, cortisol, health care provider, job strain, noradrenaline, shift worker.

Psychosocial job strain has been found to be associated with increasing long-term health risks. Job strain, which is defined as a combination of greater job demands and lower job control, (1) has been identified as a strong work-related risk factor for cardiovascular disease (CVD) (2-7). Several possible physiological mechanisms have been suggested to link job strain to an increased risk of CVD, including high blood pressure, increased blood glucose, and decreased fibrinolytic activities (8). Studies using ambulatory blood pressure measurements have provided the most convincing evidence of an association between job strain and high blood pressure (9-12).
High blood pressure, as well as other physiological changes associated with job strain, is hypothesized to be a result of responses of the stress-related neuroendocrine system (8), and the physiological influence of job strain has been examined in terms of the sympatheticadrenal medullary (SAM) system (adrenaline and noradrenaline) and the hypothalamic-pituitary-adrenal (HPA) system (cortisol). With respect to adrenaline and noradrenaline, Pollard et al (13) showed that job demands were marginally positively associated with the urinary excretion of adrenaline among men with low job control (13). Two studies showed that low job control was associated with high levels of adrenaline and

1 Department of Public Health, Hokkaido University Graduate School of Medicine, Japan.

2 Faculty of Business Administration, Hokkai-Gakuen University.

3 Department of Hygiene and Preventive Medicine, Okayama University Graduate School of Medicine and Dentistry, Japan.

4 Hokkaido Occupational Health Promotion Center.

Reprint requests to: Dr Kyoko Fujiwara, c/o Department of Hygiene and Preventive Medicine, Okayama University Graduate School of Medicine and Dentistry, 2-5-1 Shikata-cho, Okayama 700-8558, Japan. [E-mail: kkondo@med.hokudai.ac.jp] 
noradrenaline during work $(14,15)$. However, two other studies failed to show positive associations between job strain and the urinary excretion of adrenaline or noradrenaline $(16,17)$.

Higher resting levels of stress hormones and their poor recovery as a result of chronic exposure to stress should be investigated, as should the average hormone levels $(18,19)$. A literature review has suggested that a slow unwinding of stress hormones is a sensitive indicator of incomplete neuroendocrine recovery after mentally and physically demanding tasks (20), and this occurrence could be associated with long-term health risks (21). In addition, blood pressure studies consistently indicate that job strain is associated with sustained high blood pressure on a day of rest (22) and during sleep $(9,23)$, suggesting that job strain is associated with unwinding sympathetic nervous activity. One study showed elevated levels of noradrenaline and adrenaline during the night among participants with low skill discretion (a subscale of job control) (15); two others failed to show an association between job strain and urinary catecholamine excretion rates during rest after work or in the night (17) or on a day off (16). Studies investigating the association are still scarce, and those that exist were conducted using very specific samples, such as nurses who recently immigrated to the United States and prison staff $(15,17)$.

Previous findings of the association between job strain and cortisol level are also conflicting. Two studies $(24,25)$ indicated that the cortisol concentration was greater in a high job-strain group, while four studies showed an insignificant association during work $(13,22$, 26), mental tasks in a laboratory (27), or day off (13, 22). Two other studies even showed lower cortisol concentrations among participants with high job strain (28) or with high job demands (29). It should be noted, however, that the finding by Steptoe and his colleagues (28) was based on a prospective study design and that recent findings indicate an inhibited elevation of morning cortisol induced by prolonged stress, possibly because of a disturbance in the normal circadian rhythm of cortisol secretion $(21,30)$.

In our study, we investigated the associations between job strain and stress hormones (adrenaline and noradrenaline from a urine sample and salivary cortisol) during work, a rest day, and sleep among female health care providers who were rotating shifts. The aim of our study was twofold: (i) to investigate whether job strain is positively associated with adrenaline and noradrenaline excretion during work and sleep and (ii) to investigate whether job strain is associated with a decreased level of morning cortisol and thus with a flattened pattern of the circadian rhythm in cortisol excretion. We tried to measure the stress hormones at relevant frequencies to determine the circadian rhythm of cortisol. In addition, as the inconsistency of previous findings may be partly attributable to methodological problems related with incomplete adjustment for behavioral variables (total sleep time or food intake) that modify hormone levels (31-33), several confounding variables were taken into account.

\section{Participants and methods}

\section{Study design and participants}

To investigate the association between self-reported job strain and stress hormones in a cross-sectional study, we used a design measuring urinary catecholamines and salivary cortisol on a day off (catecholamines measured only during night sleep and cortisol measured three times on a day off), a day shift, and a night shift after the participants had completed a self-reported questionnaire. Eighteen female professional health care providers who worked in shifts at two institutions agreed to participate in the study. They provided care services that included physical care, assistance with housework, and general advice concerning care and welfare in the clients' homes, and it excluded medical treatment, physical examinations, and other medical care. The job demands varied according to the clients' needs and the care plan assigned to each client. The participants mainly provided physical care for elderly people and rotated shifts for 24 hours at the clients' homes. They worked alone on a day shift and with another staff member on the night shift.

One institute had a day shift from 0900 to 1730 and a night shift from 1700 to 0930 . The other had a day shift from 0830 to 1730 and a night shift from 1700 to 0900. The day shift had a lunch break from 1230 to 1330, and the night shift had a 90- to 150-minute break. The workers used the break for a nap and a meal. Some of the participants spent a little time during the break doing deskwork to record their duties. The cycle of shifts was primarily as follows: day shift, night shift, day off after night shift, and day off before day shift. The times for the three examinations were the day off before the day shift, the day shift after a day off, and the night shift after the day shift; no examinations took place during menstruation, although the menstrual cycle was not examined. Two of the examination days, the day off and the day shift, were consecutive. All of the participants avoided drugs, nicotine, caffeinated beverages, and alcohol and refrained from excessive exercise on the examination days. Furthermore, the participants who consumed these substances or did not follow the instructions regarding the collection of samples were asked to 
record the amounts and times of substances consumed, as well as the time of the food intake and the time slept on each examination day, on individual cards.

One participant was excluded from the sampling because her urine collection was incomplete, and another was excluded because the hours of sleep had been extremely short (3 hours) on the day when the urine was collected following a night's sleep (34). Therefore, the final sample included 16 women. All of them were premenopausal and from 19 to 43 years of age. They had no current history of hypertension, cardiac disease, or mental health problems. One participant had diabetes mellitus; however, her serum glucose was well controlled without medication at the time of the study. Two participants were obese, with a body mass index of 30 . The participants' job experience as a health care provider with rotating shifts was relatively short and ranged from 1 month to 2.8 years because the 24-hour rotating service in which the participants worked had been started only 2 years before.

\section{Methods}

Psychosocial job stress. We administered a self-reported questionnaire survey from 2 weeks to 1 month before the examination for salivary cortisol and urinary catecholamines. The job content questionnaire was used to measure psychosocial job stress. There had been no extraordinary changes or events at work between the time the questionnaire was administered and each examination day.

The job content questionnaire was designed to measure psychosocial job stress based on a demand-control model (1). The Japanese version of the questionnaire (version 1.7) has been validated and tested for reliability (35). This questionnaire consists of scales of job demands (5 items), job control (9 items), physical exertion (3 items), supervisory support (4 items), and coworker support (4 items). A job-strain index was calculated by dividing the score for job demands by the score for job control.

The scores for the 16 women were as follows: the average was 0.7 (SD 0.1, range 0.5-0.9) for the jobstrain index, 37 (SD 5, range 27-46) for job demands, 57 (SD 8, range 40-72) for job control, 11 (SD 3, range 4-14) for supervisory support, 12 (SD 2, range 8-16) for co-worker support, and 10 (SD 1, range 8-12) for physical exertion. Because there were so few participants, they were classified into a high group $(\mathrm{N}=8)$ and a low group $(\mathrm{N}=8)$ by the median score of the job-strain index, job demand, job control, social support or physical exertion. Table 1 shows the scores of the job content questionnaire for the high- and low-strain groups.

Biological factors. Urinary catecholamines and salivary cortisol were measured as biological outcomes. Urinary measurement of free catecholamines provided a measure of the circulating concentrations of the hormones in blood (36). Salivary cortisol was also found to be highly associated with the free cortisol fraction of the blood (37).

Urine was collected during night sleep on the day off, during the day shift, and during the night shift in a shielded portable bottle with hydrochloric acid $(6 \mathrm{~N}$, $1 \mathrm{ml})$ as an antioxidizer in a $4^{\circ} \mathrm{C}$ box. The total volume of urine was collected at one time in a big cup using a funnel. Just before beginning work the participants emptied their bladders. From that time on, they put all of their urine into one bottle from the start until the end of the shift. For sampling during the night on a day off, the participants emptied their bladders before going to bed and, if they urinated during the night, they kept the urine in a bottle until getting up the next morning. In this way, the duration of sampling during the night on a day off was almost the same as the sleeping time described in tables 2 and 3. After the total volume of urine was measured, the samples were stored at $-20^{\circ} \mathrm{C}$ after each examination. The concentrations of catecholamines were determined by high-performance liquid chromatography (HPLC) (38), and the excretion rate was calculated according to the time and weight, nanograms per kilogram per minute.

Salivary cortisol was collected at 0900,1300 , and 1900 on the day off, at 0700,0830 or 0900 (at the start of the day shift), at 1300 (on a lunch break), and at 1730 (at the end of the day shift) on the day shift, and at 1700 (at the start of the night shift), 0500, and 0900 or 0930 (at the end of the night shift) on the night shift. The participants held cotton dental rolls in their mouths for 1 minute and stored them in a salivette (Sarstedt, Leicester, United Kingdom). The salivary samples were stored at $-20^{\circ} \mathrm{C}$ after each examination. The concentration of cortisol $(\mu \mathrm{g} / \mathrm{dl})$ was determined by radioimmunoassay

Table 1. Scores of the job content questionnaire for the groups with low and high strain.

\begin{tabular}{|c|c|c|c|c|c|c|c|c|c|c|c|c|c|c|c|}
\hline \multirow[t]{2}{*}{ Group } & \multicolumn{3}{|c|}{ Job demand } & \multicolumn{3}{|c|}{ Job control } & \multicolumn{3}{|c|}{ Supervisory support } & \multicolumn{3}{|c|}{ Co-worker support } & \multicolumn{3}{|c|}{ Physical exertion } \\
\hline & Mean & SD & Range & Mean & SD & Range & Mean & SD & Range & Mean & SD & Range & Mean & SD & Range \\
\hline Low strain $(\mathrm{N}=8)$ & 35 & 5 & $27-42$ & 61 & 7 & $50-72$ & 12 & 1 & $11-13$ & 12 & 2 & $10-15$ & 10 & 1 & $8-12$ \\
\hline High strain $(\mathrm{N}=8)$ & 39 & 5 & $31-46$ & 54 & 7 & $40-62$ & 10 & 3 & $4-14$ & 12 & 2 & $8-16$ & 11 & 1 & $8-12$ \\
\hline
\end{tabular}


Table 2. Demographic variables and habitual behavior for the groups with low and high strain $(\mathrm{N}=16)$.

\begin{tabular}{|c|c|c|c|c|c|c|c|c|c|c|c|c|c|c|c|c|c|c|}
\hline \multirow[t]{2}{*}{ Group } & \multicolumn{2}{|c|}{$\begin{array}{c}\text { Age } \\
\text { (years) }\end{array}$} & \multicolumn{2}{|c|}{ Married } & \multicolumn{2}{|c|}{$\begin{array}{l}\text { Education } \\
\text { ( } \geq 14 \text { years) }\end{array}$} & \multicolumn{2}{|c|}{$\begin{array}{c}\text { Workers } \\
\text { with more } \\
\text { than one } \\
\text { child }\end{array}$} & \multicolumn{2}{|c|}{$\begin{array}{l}\text { Current } \\
\text { smoker }\end{array}$} & \multicolumn{2}{|c|}{$\begin{array}{c}\text { Number of } \\
\text { cigarettes / } \\
\text { day of the } \\
\text { smokers } \\
(N=9)\end{array}$} & \multicolumn{2}{|c|}{$\begin{array}{l}\text { Alcohol } \\
\text { consum- } \\
\text { ers }\end{array}$} & \multicolumn{2}{|c|}{$\begin{array}{l}\text { Amount of } \\
\text { ethanol / } \\
\text { week of the } \\
\text { alcohol } \\
\text { consum- } \\
\text { ers, ml } \\
(\mathrm{N}=12)\end{array}$} & \multicolumn{2}{|c|}{$\begin{array}{c}\text { Total sleep } \\
\text { hours on } \\
\text { the day } \\
\text { off, hours } \\
\text { / day }\end{array}$} \\
\hline & Mean & SD & $\mathrm{N}$ & $\%$ & $\mathrm{~N}$ & $\%$ & $\mathrm{~N}$ & $\%$ & $\mathrm{~N}$ & $\%$ & Mean & SD & $\mathrm{N}$ & $\%$ & Mean & $\mathrm{SD}$ & Mean & SD \\
\hline Low strain $(\mathrm{N}=8)$ & 29 & 8 & 3 & 38 & 5 & 63 & 2 & 25 & 5 & 63 & 10 & 7 & 6 & 75 & 29 & 16 & 8 & 1 \\
\hline High strain $(\mathrm{N}=8)$ & 28 & 6 & 1 & 13 & 4 & 50 & 1 & 13 & 4 & 50 & 23 & 5 & 6 & 75 & 123 & 114 & 7 & 2 \\
\hline
\end{tabular}

Table 3. Work-related variables and habitual behavior of the groups with low and high strain (N=16).

\begin{tabular}{|c|c|c|c|c|c|c|c|c|c|c|}
\hline \multirow[t]{2}{*}{ Group } & \multicolumn{2}{|c|}{$\begin{array}{l}\text { Domestic work, } \\
\text { sometimes or often } \\
\text { heavy burden }\end{array}$} & \multicolumn{2}{|c|}{$\begin{array}{l}\text { Duration of job } \\
\text { experience } \\
\text { (months) }\end{array}$} & \multicolumn{2}{|c|}{$\begin{array}{l}\text { Day shifts / } \\
\text { month }\end{array}$} & \multicolumn{2}{|c|}{$\begin{array}{l}\text { Night shifts / } \\
\text { month }\end{array}$} & \multicolumn{2}{|c|}{$\begin{array}{l}\text { Workhours / } \\
\text { month }\end{array}$} \\
\hline & Mean & SD & Mean & SD & Mean & SD & Mean & SD & Mean & SD \\
\hline Low strain $(\mathrm{N}=8)$ & 5 & 63 & 17 & 12 & 7 & 5 & 8 & 2 & 179 & 15 \\
\hline High strain $(\mathrm{N}=8)$ & 4 & 50 & 8 & 5 & 6 & 5 & 10 & 4 & 179 & 28 \\
\hline
\end{tabular}

Table 4. Urinary catecholamines of the two groups with low and high strain $(\mathrm{N}=16)$.

\begin{tabular}{|c|c|c|c|c|c|c|c|c|c|c|c|c|}
\hline \multirow[t]{3}{*}{ Group } & \multicolumn{6}{|c|}{ Adrenaline [ng(kg/min)] } & \multicolumn{6}{|c|}{ Noradrenaline $[\mathrm{ng}(\mathrm{kg} / \mathrm{min})]$} \\
\hline & \multicolumn{2}{|c|}{ Night sleep } & \multicolumn{2}{|c|}{ Day shift } & \multicolumn{2}{|c|}{ Night shift } & \multicolumn{2}{|c|}{ Night sleep } & \multicolumn{2}{|c|}{ Day shift } & \multicolumn{2}{|c|}{ Night shift } \\
\hline & Mean & SD & Mean & SD & Mean & SD & Mean & SD & Mean & SD & Mean & SD \\
\hline Low strain $(\mathrm{N}=8)$ & 0.09 & 0.12 & 0.28 & 0.15 & 0.21 & 0.08 & 0.83 & 0.37 & 1.51 & 0.50 & 1.59 & 0.58 \\
\hline High strain $(\mathrm{N}=8)$ & 0.11 & 0.13 & 0.25 & 0.05 & 0.16 & 0.03 & 1.08 & 0.31 & 1.62 & 0.40 & 1.28 & 0.19 \\
\hline
\end{tabular}

Table 5. Salivary cortisol of the two groups with low and high strain $(\mathrm{N}=16)$.

\begin{tabular}{|c|c|c|c|c|c|c|c|c|c|c|c|c|c|c|c|c|c|c|c|}
\hline \multirow[t]{4}{*}{ Group } & \multicolumn{19}{|c|}{ Time of measurement } \\
\hline & \multicolumn{6}{|c|}{ Cortisol on day off $(\mu \mathrm{g} / \mathrm{dl})$} & \multicolumn{8}{|c|}{ Cortisol on day shift $(\mu \mathrm{g} / \mathrm{dl})$} & \multicolumn{5}{|c|}{ Cortisol on night shift $(\mu \mathrm{g} / \mathrm{dl})$} \\
\hline & \multicolumn{2}{|c|}{0900} & \multicolumn{2}{|c|}{1300} & \multicolumn{2}{|c|}{1900} & \multicolumn{2}{|c|}{0700} & \multicolumn{2}{|c|}{0830 or 0900} & \multicolumn{2}{|c|}{1300} & \multicolumn{2}{|c|}{1730} & \multicolumn{2}{|c|}{1700} & \multicolumn{2}{|c|}{0500} & 0900 \\
\hline & Mean & SD & Mean & SD & Mean & SD & Mean & SD & Mean & SD & Mean & SD & Mean & SD & Mean & SD & Mean & $\mathrm{SD}$ & Mean SD \\
\hline Low strain $(\mathrm{N}=8)$ & 0.60 & 0.58 & 0.22 & 0.20 & 0.19 & 0.13 & 0.76 & 0.58 & 0.54 & 0.31 & 0.31 & 0.07 & 0.18 & 0.23 & 0.31 & 0.25 & 0.14 & 0.11 & $0.27 \quad 0.27$ \\
\hline High strain $(\mathrm{N}=8)$ & $0.53^{a}$ & 0.28 & 0.27 & 0.11 & 0.18 & 0.13 & $0.56^{\mathrm{a}}$ & 0.29 & 0.36 & 0.14 & 0.26 & 0.13 & $0.14^{\mathrm{a}}$ & 0.07 & 0.20 & 0.11 & 0.24 & 0.17 & $0.22^{a} 0.08$ \\
\hline
\end{tabular}

a $\mathrm{N}=7$ for high-strain group.

(RIA) (39). The catecholamines and cortisol were measured by an outside examination facility. Tables 4 and 5 show the mean and standard deviation for urinary catecholamines and salivary cortisol in the high- and lowstrain groups.

Other covariates. The questionnaire consisted of questions on demographic variables, habitual behavior (tobacco, alcohol, and sleep), domestic factors, and workrelated variables (number of times in shifts and workhours). Habitual behavior included the daily number of cigarettes smoked, the amount and type of alcohol consumed, and hours of sleep on the examina- tion day off. No information on hours slept before a night shift or day off had been collected. The alcohol intake was calculated as the average daily amount of ethanol (milliliters) estimated from the amount and type of alcohol consumed. Domestic factors included the number of children, age of youngest child, and amount of domestic work. These factors were covered by the question: "Do you think that your domestic work is a heavy burden?" The response options ranged from 1 (not at all) to 4 (frequently).

The mean value for certain characteristics of the 16 women were as follows: 28 (SD 7) years of age, 12 (SD 10) years of job experience, 7 (SD 5) day shifts per 
month, 9 (SD 3) night shifts per month, 179 (SD 22) hours of worktime per month, 15 (SD 9) cigarettes per day for current smokers ( $\mathrm{N}=9$ ), 76 (SD 92) milliliters of ethanol per week for alcohol consumers $(\mathrm{N}=12)$, and 8 (SD 1) hours of sleep on the examination day, which was the day off. Four participants were married, 9 had more than 14 years of education, 3 had more than one child, 9 sometimes or often had heavy workloads at home, 9 were current smokers, and $75 \%$ consumed alcohol.

The characteristics of the study participants separated into two groups, those with low and high strain, are shown in tables 2 and 3. Among the characteristics, there were no significant differences between the two, except for the number of cigarettes smoked per day $(\mathrm{N}=9)$.

\section{Statistical analysis}

Data were analyzed by using SPSS 10.0J (SPSS Inc, Chicago, IL, USA). Normality was evaluated by normal distribution plots for the stress hormone variables. Most of the variables (12 of 16) were normally distributed, except for adrenaline during night sleep, cortisol at 0900 on the day off, cortisol at 1730 on the day shift, and cortisol at 0900 on the night shift. The job characteristic variables were normally distributed, except for supervisory support.

A repeated-measures analysis of variance was used to examine differences in the stress hormone levels between the high- and low-strain groups and each component in the job content questionnaire, with control for age and job experience as covariates. One of the participants failed to collect a saliva sample at 0900 on her day off, at 0700 and 1730 on her day shift, and at 0500 , 0900, and 0930 on her night shift. This participant was excluded from the cortisol analyses. The mean values and their standard error for the stress hormones, adjusted for age and job experience, are shown in the figures, because poor experience may induce psychosocial stress. The comparison of the stress hormone levels between short-term job experience (less than 1 year) and long-term job experience (more than 1 year) was also assessed through the use of a repeated-measures analysis of variance.

\section{Results}

A scatter plot with the job-strain index values on the $\mathrm{x}$ axis and stress hormones at a specific time on the y-axis is shown for the 16 participants in figure 1 . The mean excretion rates and their standard errors for the adrenaline and noradrenaline levels in the high- and low-strain groups, as adjusted for age and job experience, are shown in figure 2 . We found a significantly higher excretion rate for noradrenaline $(\mathrm{N}=16, \mathrm{~F}=7.1, \mathrm{P}=0.02)$ over time in the high-strain group than in the low-strain group and in the high-demand group than in the lowdemand group $(\mathrm{N}=16, \mathrm{~F}=9.0, \mathrm{P}=0.01)$. However, the excretion of adrenaline did not significantly differ between the two groups with high and low job strain $(\mathrm{N}=16, \mathrm{~F}=0.4, \mathrm{P}=0.57)$ or the two groups with high and low job demand $(\mathrm{N}=16, \mathrm{~F}=0.2, \mathrm{P}=0.66)$. There were no differences either in the excretion rate of adrenaline $(\mathrm{N}=16, \mathrm{~F}=0.1, \mathrm{P}=0.81)$ or noradrenaline $(\mathrm{N}=16, \mathrm{~F}=0.0$, $\mathrm{P}=0.91)$ between the groups with high and low job control. Neither the effects of the examination time nor the interactions between group and time were significant for the excretion rates of the catecholamines.

The group with the most supervisory support had a significantly higher excretion rate of adrenaline than the group with low supervisory support $(\mathrm{N}=16, \mathrm{~F}=10.7$, $\mathrm{P}=0.01)$. There was no difference in the excretion rate of noradrenaline between the two groups with high and low supervisory support $(\mathrm{N}=16, \mathrm{~F}=1.0, \mathrm{P}=0.34)$. No differences in the excretion rate of adrenaline $(\mathrm{N}=16$, $\mathrm{F}=1.5, \mathrm{P}=0.25)$ or in that of noradrenaline $(\mathrm{N}=16, \mathrm{~F}=0.0$, $\mathrm{P}=0.99)$ were shown between the two groups with high and low co-worker support. Nor was there a difference in the catecholamine excretion rate between the two groups with high and low physical exertion $(\mathrm{N}=16$, $\mathrm{F}=1.1, \mathrm{P}=0.32$, and $\mathrm{N}=16, \mathrm{~F}=2.1, \mathrm{P}=0.18$, respectively).

The mean concentration and standard error of the salivary cortisol level of the high- and low-strain groups, as adjusted for age and job experience, are shown in figure 3. The concentration of cortisol on the day shift was significantly lower, but marginally, over time in the high-strain group than it was in the low-strain group $(\mathrm{N}=16, \mathrm{~F}=3.9, \mathrm{P}=0.08)$. However, there were no differences in the cortisol concentrations on the day off or on the night shift between the two groups $(\mathrm{N}=15, \mathrm{~F}=0.5$ $\mathrm{P}=0.50$, and $\mathrm{N}=14, \mathrm{~F}=0.1, \mathrm{P}=0.74$, respectively). There were no significant differences in the cortisol concentrations in the two groups with respect to any component of the job content questionnaire. Nor were there any effects of examination time or interactions between group and time with respect to cortisol concentration.

Another category, based on the tertile of the indices, which has been tested more frequently, was added. The results were similar, although statistically nonsignificant. The participants were stratified by length of job experience ( $\mathrm{N}=9$ for $<1$ year, $\mathrm{N}=7$ for $\geq 1$ year), and the same analysis was carried out. The findings were similar in both groups.

The correlation analyses showed that neither the domestic factors nor habitual behavior had an effect on the associations between job strain and stress hormones in the study findings (data not shown). 

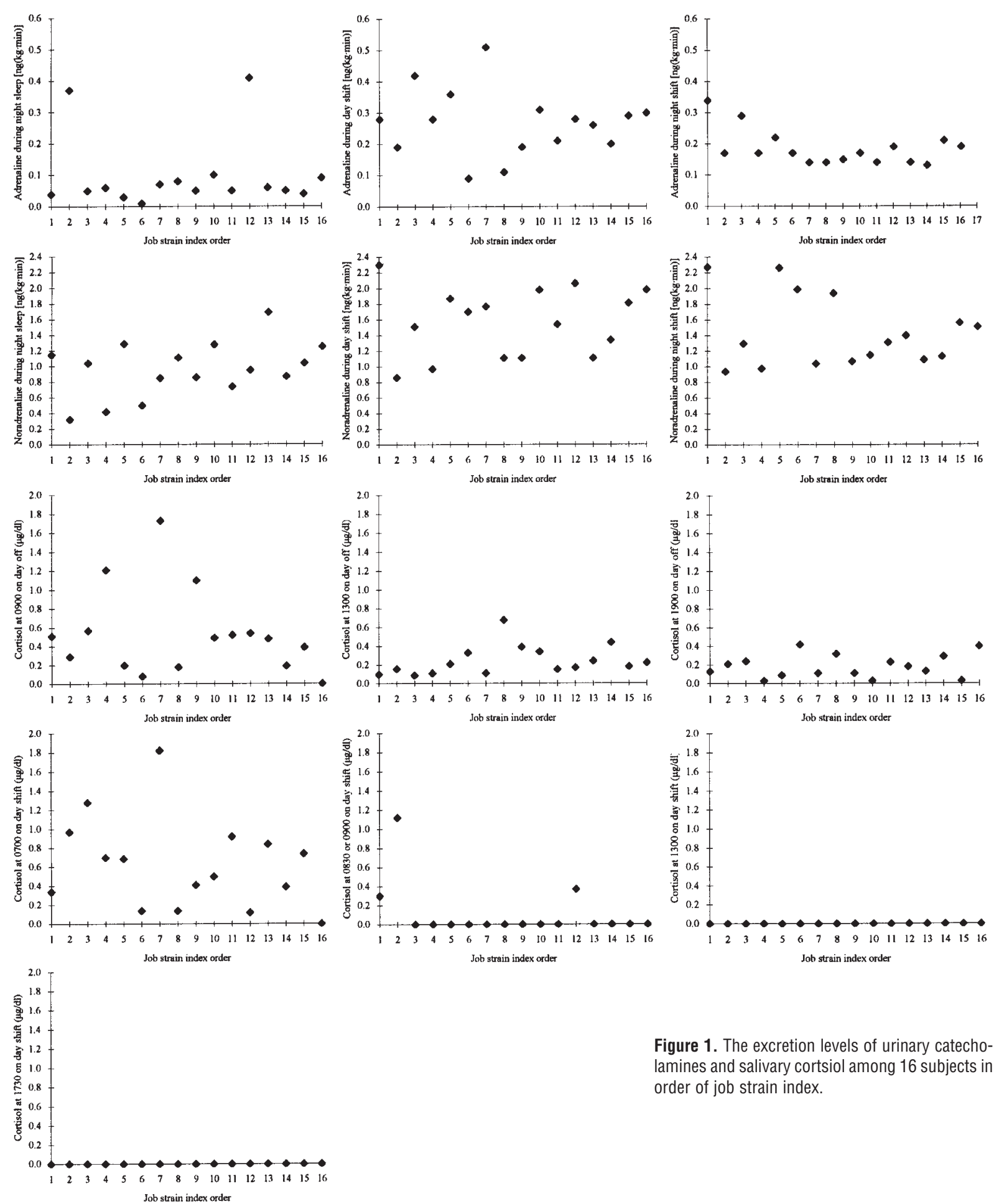

Figure 1. The excretion levels of urinary catecholamines and salivary cortsiol among 16 subjects in order of job strain index.
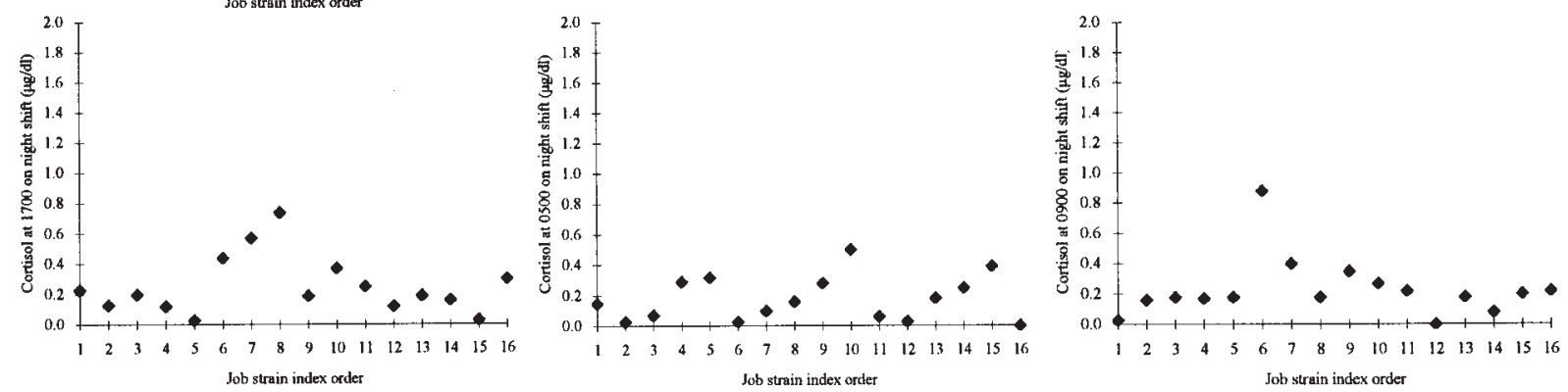


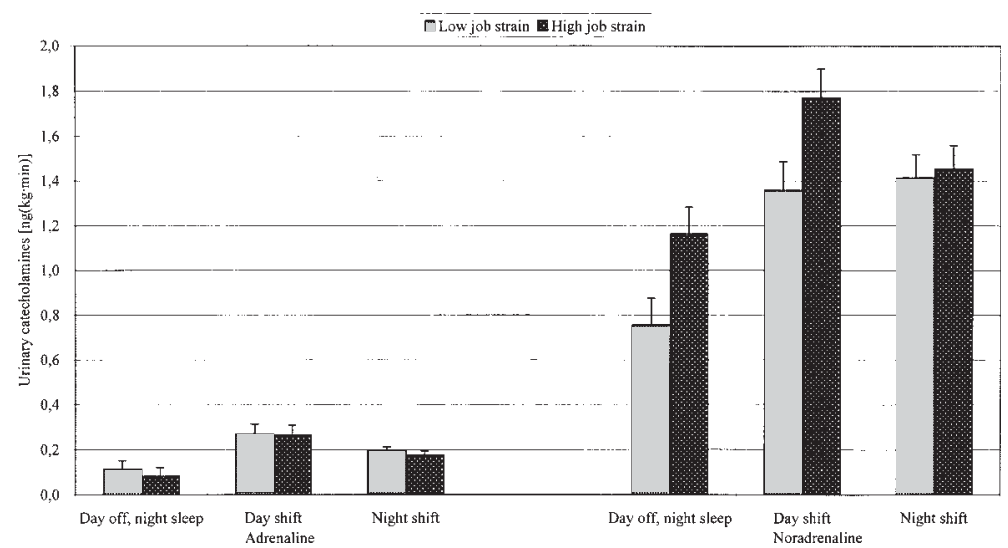

DLow job strain High job strain

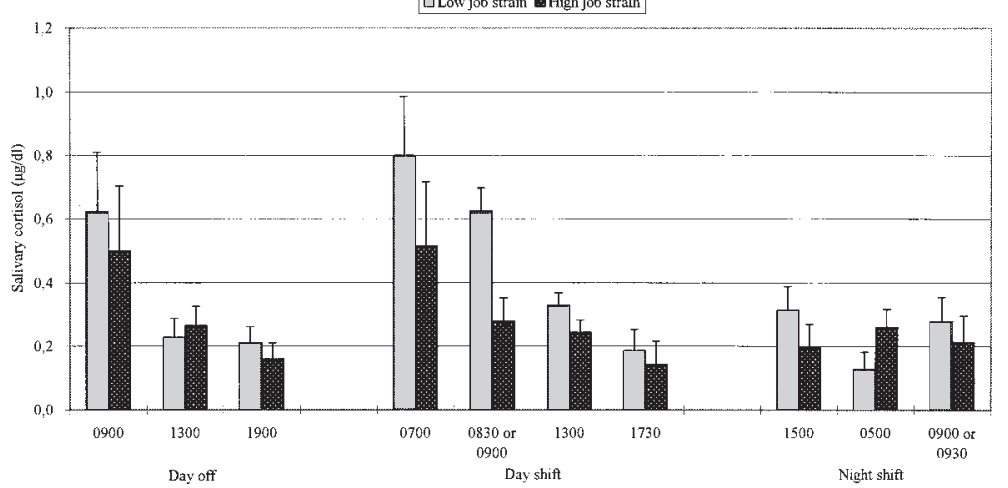

Figure 2. Mean excretion of urinary catechomines and their standard errors as adjusted for age and job experience in the high-strain $(\mathrm{N}=8)$ and low-strain $(\mathrm{N}=8)$ groups during night sleep on the day off, during the day shift, and during the night shift (repeated-measures analysis of variable).

Figure 3. Mean concentrations of salivary cortisol and their standard errors as adjusted for age and job experience in the high-strain $(\mathrm{N}=8)$ and low-strain $(\mathrm{N}=8)$ groups, during the day off, the day shift, and the night shift (repeated-measures analysis of variance). Note: the high job-strain group consisted of 7 subjects at 0900 during the day off, at 0700 and 1730 during the day shift and at 0500 and 0900 during the night shift.

\section{Discussion}

In our study, job strain was associated with a high level of noradrenaline and a low level of cortisol on the day shift among female health care providers with rotating shifts. In addition, supervisory support was associated with a high level of adrenaline. The associations were statistically significant after adjustment for relevant confounding factors, although the sample size was small. The findings partially supported the hypothesis of this study.

Noradrenaline excretion during night sleep on the day off, as well as during workdays, was higher in the participants exposed to job strain. This finding suggests that job strain is associated with sustained neuroendocrine activation during sleep on a day off, as well as on workdays. Only one study has reported an association between low skill discretion (a subscale of job control) and high noradrenaline excretion at night (15), whereas, in our study, job demands rather than job control appeared to have a stronger effect. Another previous study failed to find an association between job strain and noradrenaline excretions at night (17). Furthermore, this study did not take into account confounding factors such as age and hours of sleep on examination days. Blood pressure studies have indicated that job strain is associated with sustained high blood pressure during sleep (9, 23). Unwinding sympathetic nervous activity to keep large amounts of noradrenaline even during sleep may be a key mechanism causing blood pressure elevations, which lead to hypertension or CVD in the long run. However, the component of job strain that is associated with the stress hormone should be clarified in future studies.

Noradrenaline excretion on a workday was also greater in the group with high job strain. A repeatedmeasures analysis of variance, adding the score of physical exertion as a confounding factor, showed a similar statistical result for job strain and noradrenaline excretion $(\mathrm{N}=16, \mathrm{~F}=6.8, \mathrm{P}=0.02)$, although noradrenaline excretion represents more physical exertion. Evans \& Carrere (14) found that people who have little control over their jobs are likely to have higher levels of noradrenaline excretion on workdays. The association between job strain and noradrenaline excretion was less clear on the night shift than on the day shift in our study. This was partly attributable to the fact that the nature of the work or the demand level differed from the day to night shifts. The participants usually worked alone at a client's home on the day shift, whereas they performed their tasks with a colleague on the night shift. Working with a colleague may reduce strain and therefore induce catecholamine excretion on the night shift. The noradrenaline levels were similar on the day shift and night shift in the low job-strain group, despite the possibility of a circadian 
rhythm effect. The reason is unclear. However, the urine sample was collected only during workhours, and the noradrenaline levels mainly reflected a degree of activity during the sampling period.

We observed no significant effect of job strain on adrenaline excretion. Previous studies have shown that low job control $(14,15)$ and high job demands $(13)$ are associated with increased adrenaline levels during a workday. The method used for storing the urine samples in our survey may have diluted the effects. Laboratory studies have shown that stressful situations mainly cause an acute increase in adrenaline excretion followed by a quick decrease after the situation is under control. Prolonged stress increases noradrenaline excretion and therefore its level tends to be sustained $(40,41)$. These two hormones are derived from different physiological activities, and this difference may have affected the observation. Adrenaline reflects adrenomedullary activity and has mainly metabolic and cardiac effects, whereas noradrenaline reflects sympathoneural activity and has mainly vasoactive effects (41). Unexpectedly, the group with high supervisory support had a significantly higher excretion rate of adrenaline than the group with little supervisory support. The relationship with a supervisor may have had a particular influence for this occupation, because the participants had more administrative contact with supervisors than support at the worksite. Therefore, supervisory support may increase the excretion rate of adrenaline.

Job strain was found to be significantly associated, but marginally, with a decreased level of cortisol over time in the group with high job strain on the day shift. The morning cortisol levels (at 0900) on the day off and the night shift were particularly lower in the groups with high job strain, although the difference was nonsignificant. Previous studies have shown that job strain (28) and high job demands (29) are negatively associated with cortisol levels. Prolonged mental stress may inhibit the elevation of morning cortisol (30). The decrease in the overall mean excretion rate of stress hormones has been called "fatigue debt" by Sluiter et al (42). These findings are due to the enlargement of negative feedback or the development of progressive tolerance to the adrenal response among participants exposed to job strain. Job strain may cause a disturbance in the circadian rhythm of cortisol, and this phenomenon is also a possible alternative pathway linking job strain to ill health, including coronary heart disease. In addition, the cortisol level on the night shift in our study remained at a steady level over time (no elevation of morning cortisol) in the high-strain group. The elevation of cortisol in the morning was affected by the artificial light-dark cycle imposed on the night-shift workers (43). This pattern may have occurred because the circadian rhythm was more suppressed by high strain on the night shift.
Future studies should pay more attention to the effects of job strain on disturbances in the circadian rhythm of neuroendocrine activities.

Our study had several limitations. We might have overlooked some important associations because the study sample was small, and the statistical power may have been extremely low. Multiple comparisons should be considered because of the multiple indicators of stress hormones. In addition, the cross-sectional design precluded a causal interpretation. Therefore, care should be taken in the consideration of these findings.

The fact that the research was conducted exclusively among women limits the generalization of the findings. Future studies should replicate the study using a larger sample, men, and other occupations. Furthermore, no adjustments were made for confounding factors such as the time from awakening and eating breakfast and the menstrual cycle. It is known that cortisol excretion can be temporarily elevated after food intake (33). The time from food intake to the beginning of work was inconsistent with each participant. Four participants in the low-strain group and six participants in the high-strain group had breakfast more than 60 minutes before starting work, and the others had no breakfast at all. Therefore, it is unlikely that food intake had strong effects on the morning cortisol on the day shift. Concerning the procedure for collecting urine during a certain period of time, the time lag from hormone secretion to excretion into urine (about 30 to 60 minutes) may have affected the results $(44,45)$. It would be better to measure the stress hormones more frequently, for example, during sleep on both workdays and days off, controlling for the times of awakening and food intake. In addition, future studies should investigate the types of job demands placed on workers, such as the number of clients and the time pressures they face.

\section{Acknowledgments}

This study was entrusted to and supported by the Hokkaido Occupational Health Promotion Center. We are deeply appreciative of the support received from the staff members of the Hokkaido Occupational Health Promotion Center. We are also grateful to the people who assisted us with this study at the participating institutions.

\section{References}

1. Karasek RA. Job demands, job decision latitude, and mental strain: implications for job redesign. Adm Sci Q 
1979;24:285-311.

2. Alfredsson L, Spetz CL, Theorell T. Type of occupation and near-future hospitalization for myocardial infarction and some other diagnoses. Int J Epidemiol 1985;14(3):378-88.

3. Johnson JV, Hall EM. Job strain, work place social support, and cardiovascular disease: a cross-sectional study of a random sample of the Swedish working population. Am J Public Health 1988;78(10):1336-42.

4. Johnson JV, Hall EM, Theorell T. Combined effects of job strain and social isolation on cardiovascular disease morbidity and mortality in a random sample of the Swedish male working population. Scand J Work Environ Health 1989;15:271-9.

5. Theorell T, Perski A, Orth-Gomér K, Hamsten A, de Faire U. The effects of the job strain of returning to work on the risk of cardiac death after a first myocardial infarction before the age of 45. Int J Cardiol 1991;30(1):61-7.

6. Bosma H, Marmot MG, Hemingway H, Nicholson AC, Brunner E, Stansfeld SA. Low job control and risk of coronary heart disease in Whitehall II (prospective cohort) study. BMJ 1997;314(7080):558-65.

7. Bosma H, Peter R, Siegrist J, Marmot M. Two alternative job stress models and the risk of coronary heart disease. Am J Public Health 1998;88(1):68-74.

8. Schnall PL, Landsbergis PA, Baker D. Job strain and cardiovascular disease. Annu Rev Public Health 1994;15:381-411.

9. Theorell T, de Faire U, Johnson J, Hall E, Persli A, Stewart W. Job strain and ambulatory blood pressure profiles. Scand J Work Environ Health 1991;17:380-5.

10. Landsbergis PA, Schnall PL, Warren K, Pickering TG, Schwartz JE. Association between ambulatory blood pressure and alternative formulations of job strain. Scand J Work Environ Health 1994;20:349-363.

11. Schnall PL, Schwarts JE, Landsbergis PA, Warren K, Pickering TG. A longitudinal study of job strain and ambulatory blood pressure: results from a three-year follow-up. Psychosom Med 1998;60(6):697-706.

12. Brisson C, Laflamme N, Moisan J, Milot A, Mâsse B, Vézina M. Effects of family responsibilities and job strain on ambulatory blood pressure among white-collar women. Psychosom Med 1999;61(2):205-13.

13. Pollard TM, Ungpakorn G, Harrison GA, Parkes KR. Epinephrine and cortisol responses to work: a test of the models of Frankenhhaeuser and Karasek. Annu Behav Med 1996;18(4):229-37.

14. Evans GW, Carrere S. Traffic congestion, perceived control, and psychophysiological stress among urban bus drivers. J Appl Psychol 1991;76(5):658-63.

15. Harenstam AB, Theorell TP. Work conditions and urinary excretion of catecholamines-a study of prison staff in Sweden. Scand J Work Environ Health 1988;14:257-64.

16. Van der Beek AJ, Meijman TF, Frings-Dresen MHW, Kuiper JI, Kuiper S. Lorry drivers' work stress evaluated by catecholamines excreted in urine. Occup Environ Med 1995;52:4649.

17. Brown DE, James GD. Physiological stress responses in Filipino-American immigrant nurses: the effects of residence time, life-style, and job strain. Psychosom Med 2000;62(3):394-400.

18. Dienstbier RA. Arousal and physiological toughness: interpersonal interaction and cardiovascular response in Type A subjects. Psychol Rev 1989;96(1):84-100.

19. Schaubroeck J, Ganster DC. Chronic demands and responsively to challenge. J Appl Psychol 1993;78(1):73-85.
20. Sluiter JK, Frings-Dresen MHW, Meijman TF, Van der Beek AJ. Reactivity and recovery from different types of work measured by catecholamines and cortisol: a systematic literature overview. Occup Environ Med 2000;57:298-315.

21. Bjorntorp P. Heart and soul: stress and the metabolic syndrome. Scand Cardiovase J 2001;35:172-7.

22. Theorell T, Ahlberg-Hulten G, Jodko M, Sigala F, de la Torre B. Influence of job strain and emotion on blood pressure in female hospital personnel during workhours. Scand J Work Environ Health 1993;19:313-8.

23. Rau R, Georgiades A, Fredrikson M, Lemne C, De Faire U. Psychosocial work characteristics and perceived control in relation to cardiovascular rewind at night. J Occup Health Psychol 2001;6(3):171-81.

24. Fox ML, Dwyer D, Ganster DC. Effects of stressful job demands and control on physiological and attitudinal outcomes in a hospital setting. Acad Manage J 1993;36(2):289318.

25. Steptoe A, Cropley M, Griffith J, Krischbaum C. Job strain and anger expression predict early morning elevations in salivary cortisol. Psychosom Med 2000;62(2):286-92.

26. Ohlson CG, Soderfeldt M, Soderfeldt B, Jones I, Theorell T. Stress markers in relation to job strain in human services organizations. Psychother Psychosom 2001;70(5):268-75.

27. Steptoe A, Fieldman G, Evans O, Perry L. Control over work pace, job strain, and cardiovascular responses in middle-aged men. J Hypertens 1993;11(7):751-9.

28. Steptoe A, Wadle J, Lipsey Z, Oliver G, Kirschbaum C. A longitudinal study of workload and variations in psychological well-being, cortisol, smoking, and alcohol consumption. Annu Behav Med 1998;20(2):84-91.

29. Sluiter JK, Frings-Dresen MHW, van der Beek AJ, Meijman TF, Heisterkamp SH. Neuroendocrine reactivity and recovery from work with different physical and mental demands. Scand J Work Environ Health 2000;26(4):306-16.

30. Fukuda S, Morimoto K. Lifestyle, stress, and cortisol response: a review I mental stress-. Environ Health Prev Med 2001;6:9-14.

31. Lundberg U. Human psychobiology in Scandinavia II psychoneuroendocrinology: human stress and coping process. Scand J Psychol 1984;25:214-26.

32. Costa G, Ghirlanda G, Tarondi G, Minors D, Waterhouse J. Evaluation of a rapidly rotating shift system for tolerance of nurses to night work. Int Arch Occup Environ Health 1994;65(5):305-11.

33. Vicennati V, Ceroni L, Gagliardi L, Gambineri A, Pasquali R. Response of the hypothalamic-pituitary-adrenocortical axis to high-protein/fat and high-carbohydrate meals in women with different obesity phenotypes. J Clin Endocrinol Metab 2002;87(8):3984-8.

34. Åkerstedt T, Gillberg M. Circadian variation of catecholamine excretion and sleep. Eur J Appl Physiol 1983;51:20310.

35. Kawakami N, Kobayashi F, Araki S, Haratani T, Furui H. Assessment of job stress dimensions based on the job demands-a control model of employees of telecommunication and electric power companies in Japan: reliability and validity of the Japanese version of the job content questionnaire. Int J Behav Med 1995;2(4):358-75.

36. Moleman P, Tulen JHM, Blankestijn PJ, Man in't Veld AJ, Boomsma F. Urinary excretion of catecholamines and their metabolites in relation to circulating catecholamines. Arch Gen Psychiatry 1992;49:568-72.

37. Krischbaum C, Hellhammer DH. Salivary cortisol in psy- 
choneuroendocrine research: recent developments and applications. Psychoneuroendocrinology 1994;19(4):313-33.

38. Boos KS, Wilmers B, Sauerbrey R, Schlimme E. Development and performance of an automated HPLC-analyzer for catecholamines. Chromatographia 1987;24:363-70.

39. Dressendorfer RA, Kirschbaum C, Rohde W, Stahl F, Strasburger CJ. Synthesis of a cortisol-biotin conjugate and evaluation as a tracer in an immunoassay for salivary cortisol measurement. J Steroid Biochem Mol Biol 1992;43(7):68392.

40. Miki K, Sudo A. An increase in noradrenaline excretion during prolonged mental task load. Ind Health 1997;35:5560.

41. Piercecchi-Marti MD, Leonetti G, Pelissier AL, Conrath J, Cianfareni F, Valli M. Evaluation of biological stress markers in police officers. Med Law 1999;18(1):125-44.
42. Sluiter JK, Van der Beek AJ, Frings-Dresen MHW. Work stress and recovery measured by urinary catecholamines and cortisol excretion in long-distance coach drivers. Occup Environ Med 1998;55:407-13.

43. Goichot B, Weibel L, Chapotot F, Gronfier C, Piquard F, Brandenberger G. Effect of the shift of the sleep-awake cycle on three robust endocrine markers of the circadian clock. Endocrinol Metab 1998;275(2):243-8.

44. Åkerstedt T, Gillberg M, Hjemdahl P, Sigurdson K, Gustavsson I, Daleskog M, et al. Comparison of urinary and plasma catecholamine response to mental stress. Acta Physiol Scand 1983;117:19-26.

45. Cohen S, Kesseler RC, Gordon LU, editors. Measuring stress. Oxford: Oxford University Press; 1997.

Received for publication: 19 June 2003 